Danmarks geologiske Undersøgelse.

II. Række Nr. 20.

\title{
Bidrag til Danmarks tertiære og diluviale Flora.
}

Af

N. Hartz.

Atlas.

København.

I Kommission hos C. A. Reitzel.

Fr. Bagges Kgl. Hof-Bogtrykkeri.

1909. 


\section{Fortegnelse over Danmarks geologiske Undersøgelses Skrifter.}

\section{Række.}

Beskrivelser til Geologisk Kort over Danmark i Maalestok 1:100000.

Nr. 1. K. RøвDam. Kortbladene Helsingør og Hillerød.

$1893 \ldots \ldots \ldots \ldots \ldots \ldots \ldots \ldots \ldots$ Pris $2,00 \mathrm{Kr}$.

- 2. N. V. Ussing og Victor Madsen. Kortbladet

Hindsholm. $1897 \ldots \ldots \ldots \ldots \ldots \ldots \ldots \ldots-2,00-$

- 3. A. Jessen. Kortbladene Skagen, Hirshals, Frederikshavn, Hjøring og Løkken. $1899 \ldots \ldots-6,00 \quad-$

- 4. A. Jessen. Kortbladene Læsø og Anholt. 1897. - 1,50 -

- 5. Victor Madsen. Kortbladet Samsø. $1897 \ldots \ldots$ - . 1,50 -

- 6. K. Røврам. Kortbladene Kjøbenhavn og Roskilde. $1899 \ldots \ldots \ldots \ldots \ldots \ldots \ldots \ldots \ldots \ldots \ldots \ldots \ldots \ldots \ldots$ - $4,00 \ldots \ldots$ -

- 7. Victor Madsen. Kortbladet Bogense. $1900 \ldots \ldots-2,00$ -

- 8. K. Rørdam og V. MrLthers. Kortbladene Sejrø,

Nykjøbing, Kalundborg og Holbæk. $1900-5,00-$

- 9. Victor Madsen. Kortbladet Nyborg. 1902 ... - 4,50 -

- 10. A. Jessen. Kortbladene Aalborg og Nibe (nordlige Del). $1905 \ldots \ldots \ldots \ldots \ldots \ldots \ldots \ldots \ldots \ldots \ldots \ldots \ldots \ldots$ - $4,50-$

- 11. V. Milthers. Kortbladene Faxe og Stevns Klint.

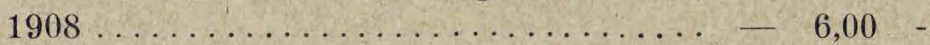

- 12. A. Jessen. Kortbladet Skamlingsbanke. 1907 . _ 2,00 -

\section{Række. \\ Afhandlinger om specielle, videnskabelige og praktiske Emner.}

Nr. 1. K. RøRDam. Undersøgelse af mesozoiske Lerarter og Kaolin paa Bornholm i geologisk og teknisk Henseende. $1890 \ldots \ldots \ldots \ldots$ Pris $1,25 \mathrm{Kr}$. 
Danmarks geologiske Undersøgelse.

II. Række Nr. 20.

\section{Bidrag til Danmarks tertiære og diluviale Flora.}

Af

N. Hartz.

\section{Atlas.}

København.

I Kommission hos C. A. Reitzel.

Fr. Bagges Kgl. Hof-Bogtrykkeri.

1909. 


\section{Register til Tavlefigurerne.}

\begin{tabular}{|c|c|c|}
\hline Acer sp....... & XII. 5 & Elcocarpus globulus P. Menz \\
\hline Ajuga reptans............ & XI. 27 & Empetrum nigrum....... \\
\hline Alnus sp.(Kefersteinii Goepp.?) & III. $5-8$ & Enodium (Molinia) coeruleum \\
\hline Betula nana........... & X. $4-5$ & Entorrhiza vaccinii E. Rostr \\
\hline$\ll \quad$ sp. ............ & III. 9 & Eoliter . . . . . . . . . \\
\hline Brasenia purpurea Мichх... & V. 17-21 & Erirhinus sp.? ......... \\
\hline Callitriche autumnalis..... & VII. 8 & Eupatorium cannabinum... \\
\hline Carpinus betulus ......... & XII. $3--4$ & Gnomonia sp........... \\
\hline Carpolithes A. ........... & III. $17-18$ & Hemiaulus sp. .......... \\
\hline B. $\ldots \ldots \ldots \ldots$ & III. $19-20$ & Hydrocharis morsus rance. \\
\hline Dalgasii m. . . . & III. 10 & $\ll \quad$ tertiaria $\mathrm{m} . .$. \\
\hline Furensis $\mathrm{m} . .$. . & II. 3 & Ilex aquifolium . . IX. 12-13, XI. 25-26 \\
\hline Hafniensis m... & V. 6 & Lastrcea thelypteris ........ IX. 8-11 \\
\hline Johnstrupii m. . & III. $11-13$ & Limnanthemum nymphaoi- \\
\hline « $\quad \mathrm{m}$. . & IV. $18-21$ & des $\ldots \ldots \ldots \ldots \ldots \ldots$ \\
\hline le Mairii m. ... & IV. 16 & Lycopus europaus........ \\
\hline Nyssoides m.... & III. $14-16$ & Marchantia polymorpha.... \\
\hline Ordrupensis m. . & IV. 10 & Melosira sp. . . . . . . . . \\
\hline rhabdospermus & & Mycorrhiza sp.......... \\
\hline & II. 5 & Oenanthe phellandrium .... \\
\hline Rosenkjcerii .... & IV. $11-15$ & Osmunda regalis .......... \\
\hline Steenstrupii m.. & IV. $22-23$ & Oxalis acetosella ......... \\
\hline Østrupii m. .... & IV. $25-26$ & Phryganide............ \\
\hline Carum carvi?.......... & XII. $16-17$ & Phyllites sp. $\ldots \ldots \ldots \ldots \ldots$ I. 2 \\
\hline Ceratophyllum demersum .. & IV. 27 & Picea excelsa....... VII. 18, IX. 16--18, \\
\hline Cervide (Cervus dama?).... & VI. $7-11$ & X. $1-2,6$, XI. $7-11$ \\
\hline Cicuta virosa? . . . . . . . . & XII. 15 & Pinnularia Brauni Grun. var. $\quad$ III. 23 \\
\hline Cirsium lanceolatum....... & XII. $6-7$ & Pinus efr. Hageni Hr. ..... \\
\hline Cocculites Kanei Нr....... & I. 1 , II. 1 & " Laricio Thomasiana \\
\hline Corylus avellana f. oblonga & XIII. $15-25$ & HeEr. . . . . . . . \\
\hline " $\quad$ f. ovata.. & XIII. $10-14$ & cfr. Laricio Thomasi- \\
\hline " $\quad$ f. silvestris & XIII. $1-9$ & ana Нв.......... \\
\hline Drosera rotundifolia....... & VI. 5 & silvestris. . . . . . . \\
\hline Dulichium spathaceum..... & $\begin{array}{l}\text { VII. } 9-16, \\
1-2, \times, 3\end{array}$ & $\begin{array}{l}\text { Piscicola sp. } \ldots \ldots \ldots \ldots \ldots \\
\text { Plumatella sp. . . . . . }\end{array}$ \\
\hline
\end{tabular}


Polygonum lapathifolium .. XII. 20

Populus tremula..... VII. 17, XI. 14-18

Potentilla anserina ........ IV. 24

Prunus padus............ VI. 6

Pteris efr. Parschlugiana UNG. III. 1

Rubus sp. ............ XII. 23-24

Rumex maritimus ........ VII. 3

« sp. ............ XI. 19-20

Sagittaria sagittafolia ..... X. XI. 21

Sambucus sp.......... IV. 28, XII. 21 Sequoia Langsdorfii Brngt.

sp. ............ III. $3-4$

Sparganium ramosum. V. $14-16$, IX. 15

Stauroneis $\operatorname{sp} . \ldots \ldots \ldots \ldots$ III. 24
Stratiotes aloides .... IV. 5-6, IX. 1-7

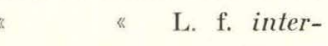

Taphrina alni .......... XI. 4

Taxus baccata ........... XI. $12-13$

Tilia europска.......... XII. 9-10

« grandifolia......... VII. 2

Torilis anthriscus ........ XII. 11-12

Ulmus sp. ........... XI. 22-24

Viola palustris........... XII. 22

Viscum album .......... X. X. 28-29

Vitis teutonica A. BR....... VI. 17

Med Undtagelse af T. III, Fig. 23-25, der er tegnede af Hr. E. Østrup og T. III, Fig. 1, 10 og 19, der er tegnede af Hr. H. Olrik, er alle Tegningerne udførte af Hr. E. Dithevsen. 
Tavle I 


\section{Planter fra Cementsten.}

Fig. 1. Cocculites Kanei Hr. $\frac{1}{1}$, Nordstranden af Fur. S. 15.

Fig. 2. Phyllites sp. $\frac{1}{1}$, Klitgaard, Mors. S. 17. 
D. G. U. II R. Nr. 20.

Tavle I.

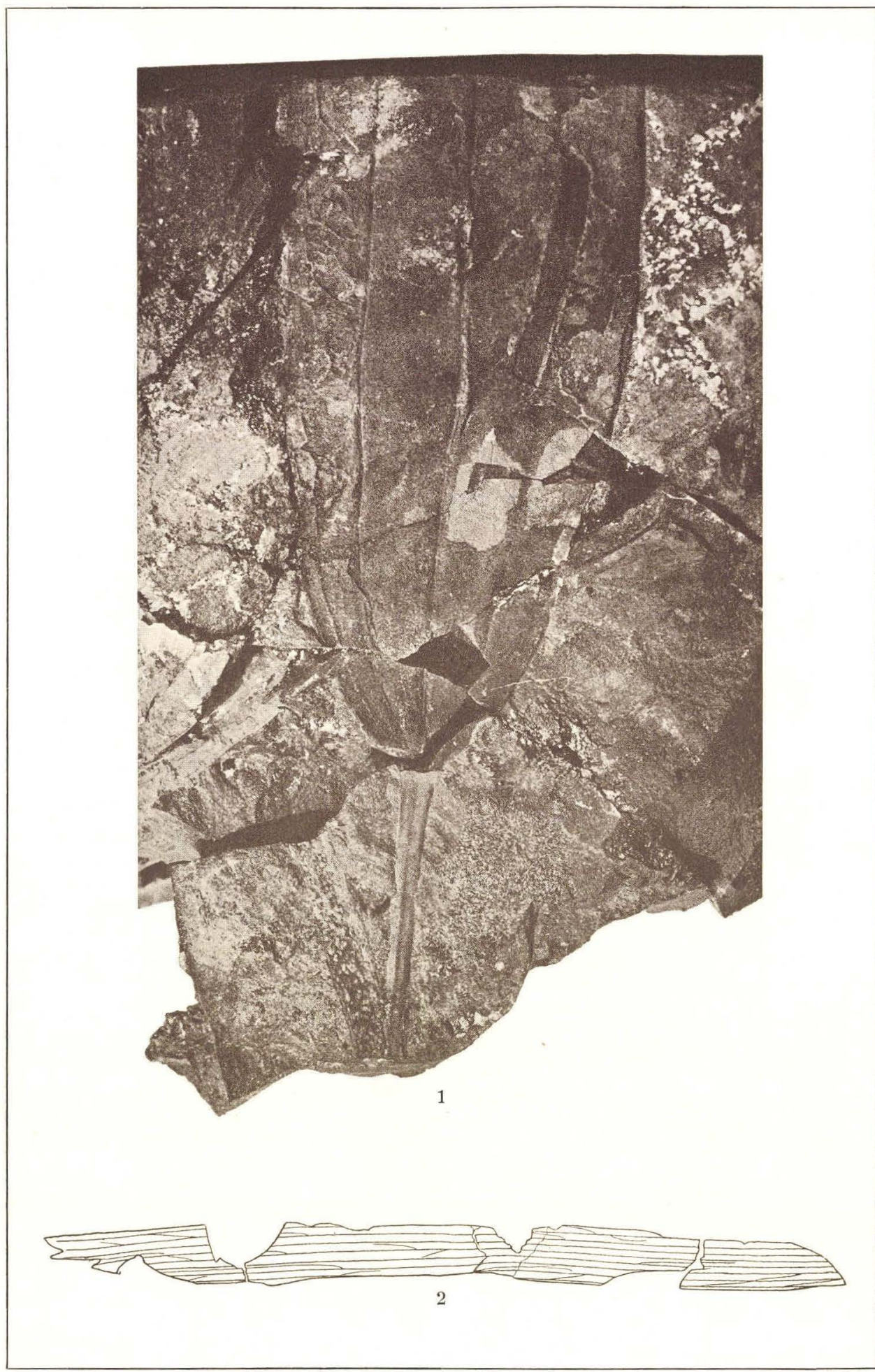


Tavle II 


\section{Planter fra Cementsten.}

Fig. 1. Cocculites Kanei Hr. $\frac{1}{1}$, Hanklit, Mors. S. 15.

Fig. 2. Pinus cfr. Laricio Thomasiana Hr. $\frac{1}{1}$, Mors. S. 12.

Fig. 3. Carpolithes Furensis m. Nordstranden af Fur. S. 15.

Fig. 4. Erirhinus sp? Brothen, Holsten. S. 18.

Fig. 5. Carpolithes rhabdospermus (Leso.) m. Brothen, Holsten. S. 18. 
D. G. U. II R. Nr. 20.

Tavle II.

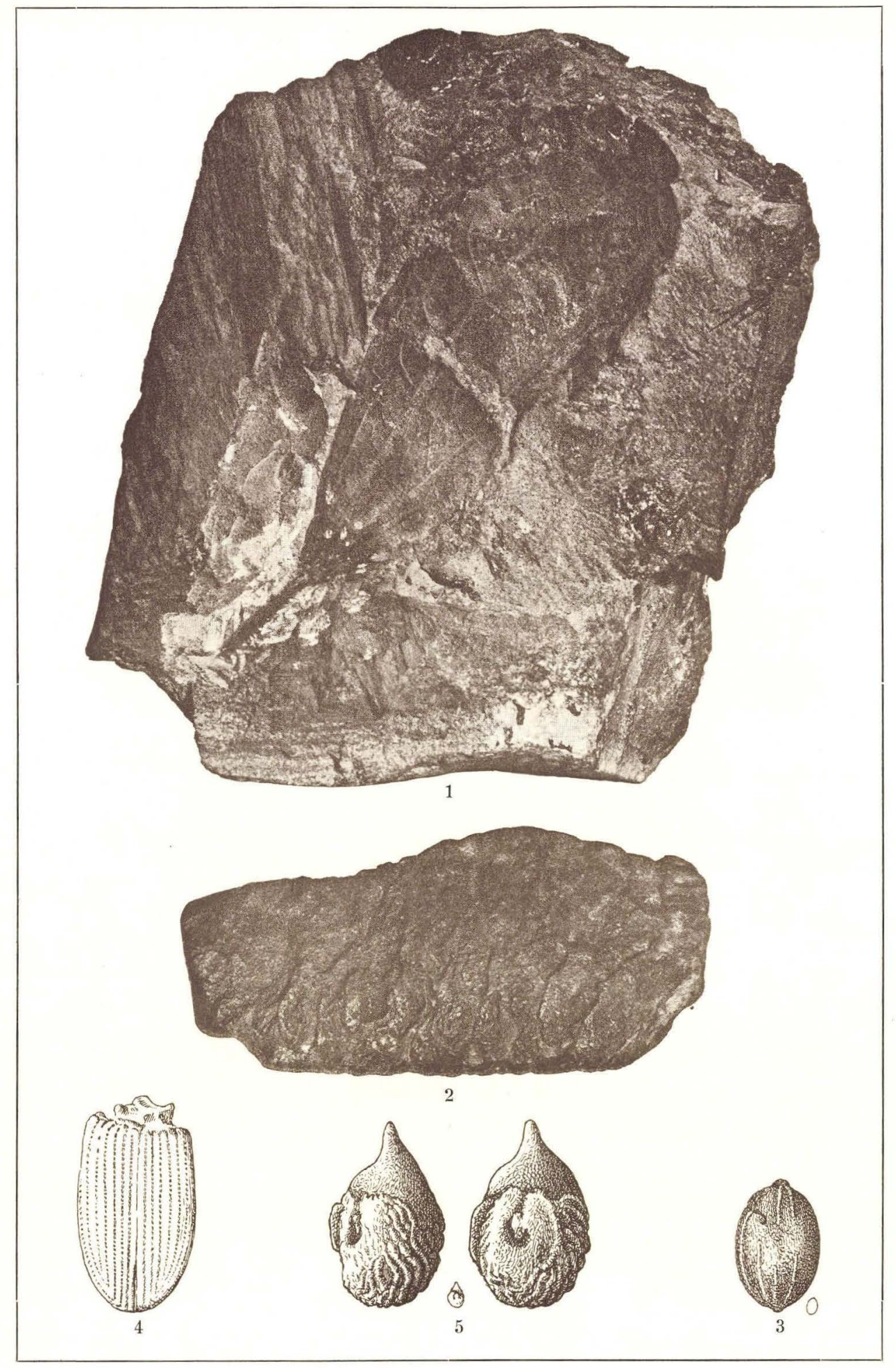


Tavle III 


\section{Planter fra Brunkul.}

Fig. 1. Pteris cfr. Parschlugiana UNG. Et fragmentarisk Smaablad. $\frac{4}{3}$, Gytje, Salten. S. 55.

Fig. 2. Pinus Laricio Thomasiana Heer. $\frac{1}{1}$, Gytje, Sønderskov. S. 55.

Fig. 3-4. Sequoia Langsdorfii Brngt. sp. Fig. 3.: Gytje, Salten. Fig. 4.: Gytje, Sønderskov. S. 56.

Fig. 5-8. Alnus sp. (Kefersteinii Goepp.?) Gytje, Fig. 5-6 Salten. Fig. 7-8 Sønderskov. S. $56-57$.

Fig. 9. Betula sp. $\frac{1}{1}$, Gytje, Salten. S. 57.

Fig. 10. Carpolithes Dalgasii m. Gytje, $\frac{9}{1}$, Sønderskov. S. 58.

Fig. 11-13. Carpolithes Johnstrupii m. Fig. 11. En Carpolith, kuglerund, spaltet $\mathrm{i}$ to Halvdele (a og b), begge set indvendig, c udvendig. Brunkul, Sønderskov. S. 58. Fig. 12. En fladtrykt og spaltet Carpolith set indvendig og udvendig. Salten. Fig. 13. En fladtrykt Carpolith, noget større end de fleste andre Eksemplarer. Salten. S. 58.

Fig. 14-16. Carpolithes Nyssoides m. Fig. 14-15 Salten. Fig. 16 Sønderskov. S. $58-59$,

Fig. 17-18. Carpolithes A. Gytje, Sønderskov. S. 59.

Fig. 19. Carpolithes B. Gytje, Sønderskov. S. 59.

Fig. 20. Carpolithes B? Gytje, Salten. S. 59.

Fig. 21. Hydrocharis tertiaria m. Gytje, Sønderskov. S. 59.

Fig. 22. Melosira sp. $\frac{1000}{1}$. Brunkul B; Sønderskov. S. 63. del. E. Østrup.

Fig. 23. Pinnularia Brauni Grun. var. $\frac{1000}{1}$. Gytje; Sønderskov. S. 63. del. E. Østrup.

Fig. 24. Stauroneis sp. $\frac{1000}{1}$. Glimmerler; Sandfeldgaard. S. 63. del. E. Østrup.

Fig. 25. Hemiaulus sp. $\frac{1000}{1}$. Gytje; Sønderskov. S. 63. del. E. Øsтrup. 
D. G. U. II R. Nr. 20.

Tavle III.

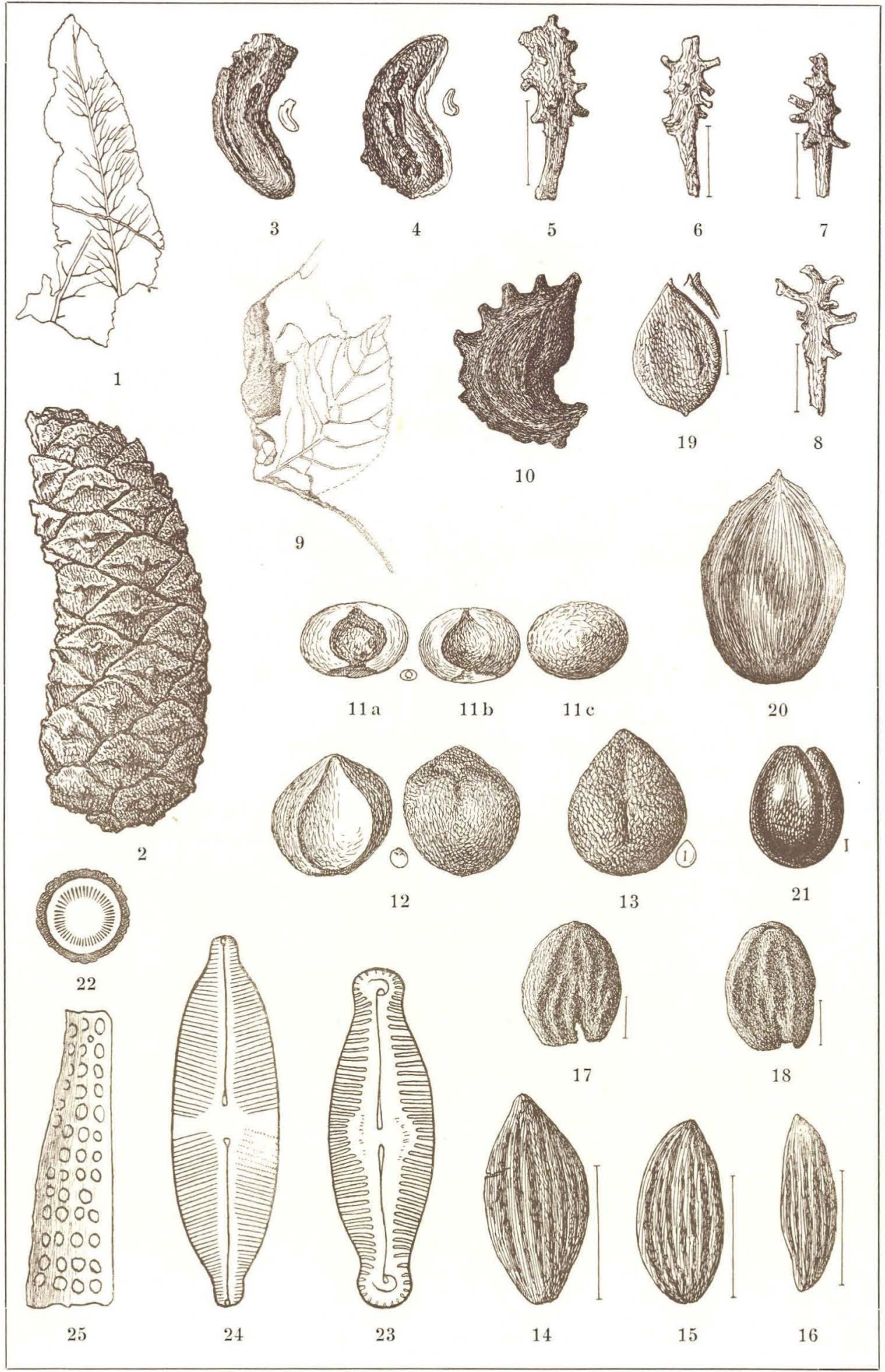


Tavle IV 


\section{Planter fra Rav-Pindelag m. m.}

Fig. 1-2. Stratiotes Kaltennordhemensis (ZENk.). Valby Bakke. S. 125.

Fig. 3-4. Stratiotes aloides L. f. intermedia m. Præglacial Gytje ved Eime, Hannover. S. 126.

Fig. 5-6. Stratiotes aloides L. Interglacial Mose, Tuesbøl Mark ved Brørup. S. $126-127$.

Fig. 7-8. Stratiotes Kaltennordhemensis (Zenk.). Valby Bakke. S. 125.

Fig. 9. Stratiotes aloides L. f. intermedia m. Valby Bakke. S. 126.

Fig. 10. Carpolithes Ordrupensis m. Ordrup. S. 123.

Fig. 11-15. Carpolithes Rosenkjarii m. Fig. 11 med Klap, Fig. 12 uden Klap, Fig. 13 i Tværsnit, Fig. 14 uregelmæssigt formet, med 2 Klapper, Fig. 15 en firerummet Carpolith med 2 Klapper, set fra Basis og fra Toppen. Valby Bakke. S. 123.

Fig. 16. Carpolithes le Mairii m. Valby Bakke. S. 123.

Fig. 17. Vitis teutonica A. Br. Valby Bakke. S. 125.

Fig. 18-21. Carpolithes Johnstrupii m. Valby Bakke. S. 123.

Fig. 22-23. Carpolithes Steenstrupii m. Valby Bakke. S. 124.

Fig. 24. Potentilla anserina. Valby Bakke. S. 124.

Fig. 25-26. Carpolithes Østrupii m. Kalvebodstrand. S. 124.

Fig. 27. Ceratophyllum demersum. Kalvebodstrand. S. 126.

Fig. 28. Sambucus sp. Bovbjerg. S. 126. 


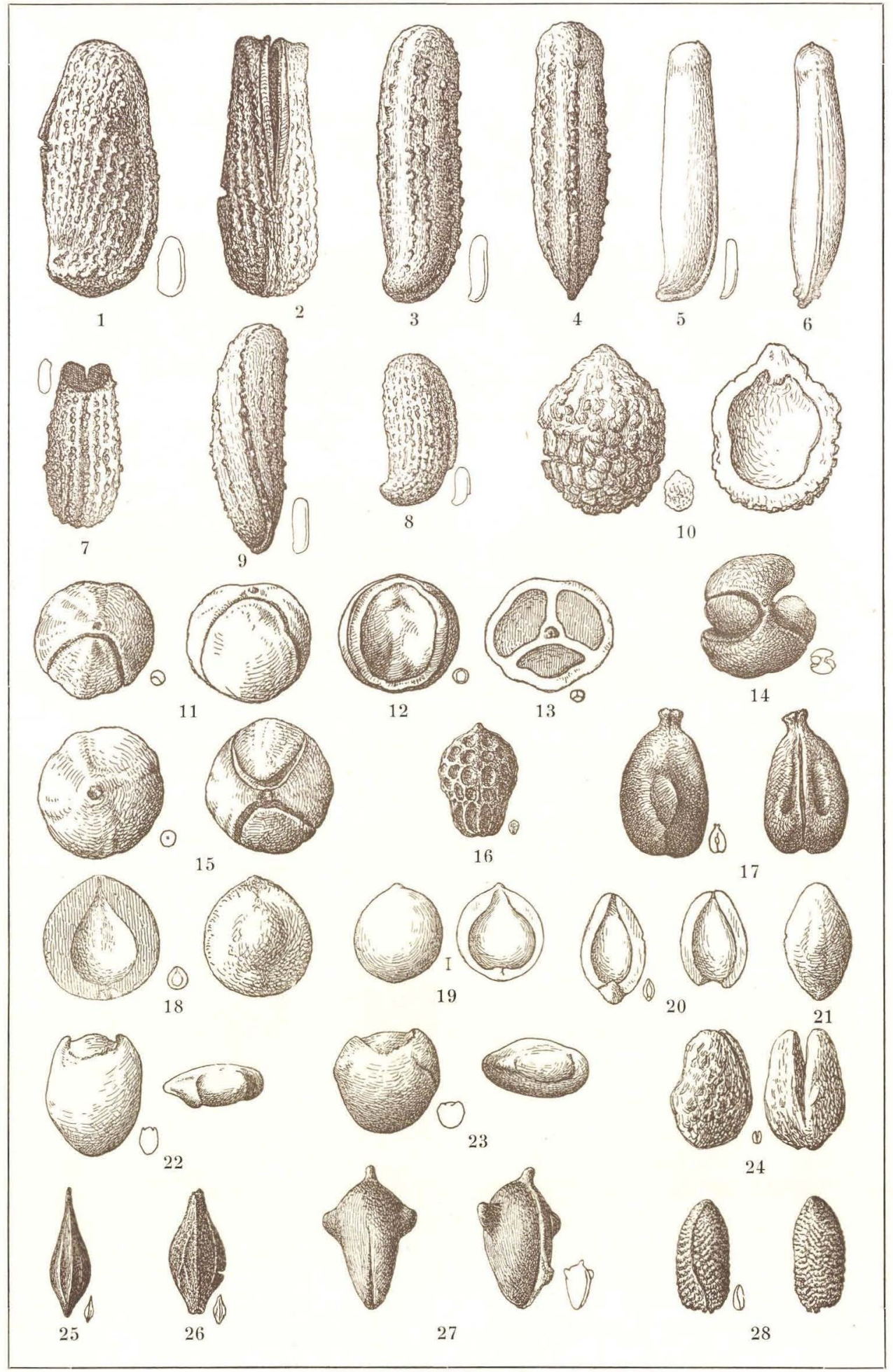


Tavle V 


\section{Planter fra Rav-Pindelag m. m.}

Fig. 1. Elcoocarpus globulus P. Menz. Brunkul, Senftenberg, Nieder Lausitz, leg. N. Hartz 1898. S. 124.

Fig. 2-5. Elcoocarpus globulus P. Menz. Valby Bakke. S. 124.

Fig. 6. Carpolithes Hafniensis m. Fig. 6 a set fra Siden, $6 \mathrm{~b}$ set fra Toppen, $6 \mathrm{c}$ set fra Basis. Valby Bakke. S. 122.

Fig. 7. Pinus cfr. Hageni Hr. Kalvebodstrand. S. 122.

Fig. 8-13. Pinus silvestris. Rullede Kogler og "Kogletene». Valby Bakke. S. 125.

Fig. 14-16. Sparganium ramosum. Sammenvoksede Frugtstene. Fig. 14 dannet ved Sammenvoksning af 2 Frugtstene (set fra Siden og Toppen), Fig. 15 af 3 (set fra Siden, Basis og Toppen) og Fig. 16 af 4 Frugtstene (set fra Siden og Toppen). Valby Bakke. S. 126.

Fig. 17-21. Brasenia purpurea Michx., forstørrede Kopier efter Gunnar Andersson (1896, Tavle I, Fig. $3-5$ og $9-10$ ). Ordrup. S. 122. 

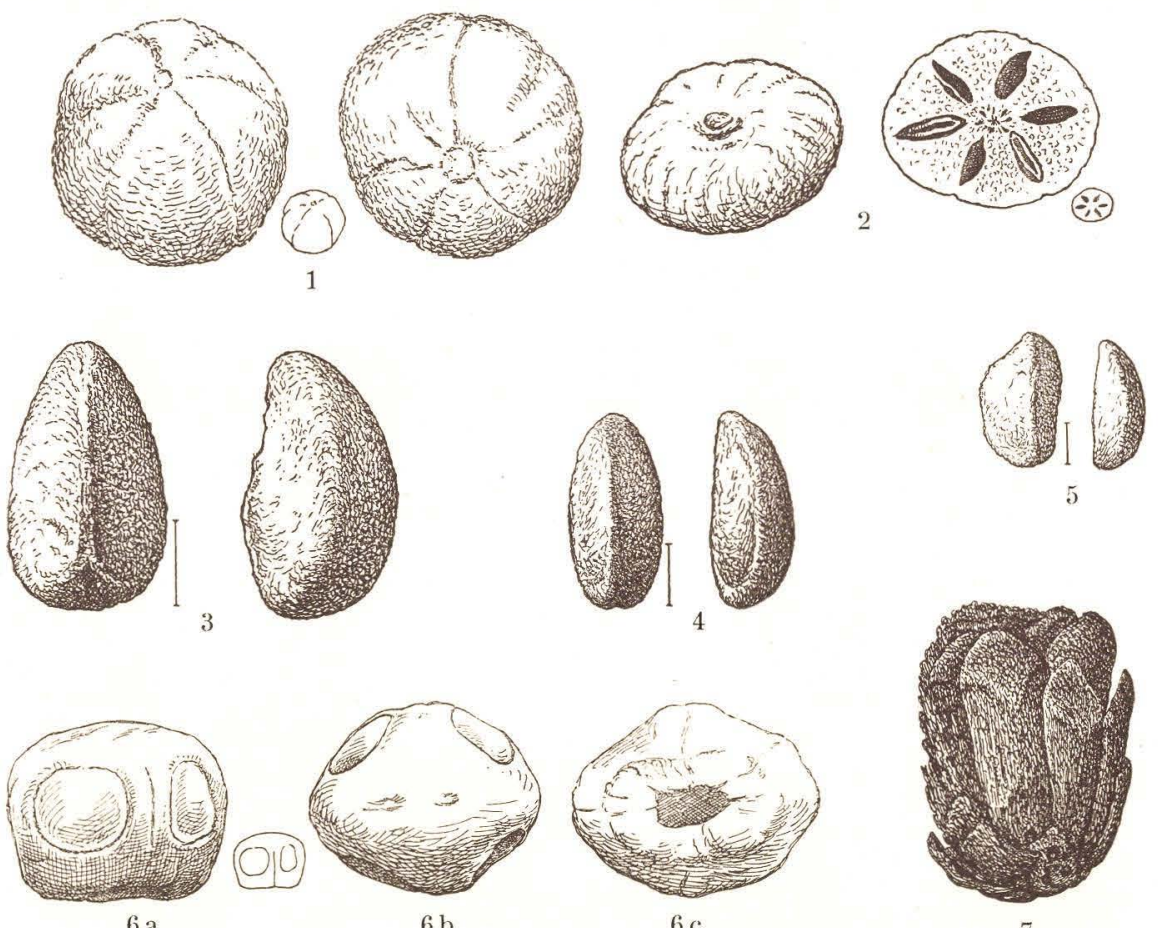

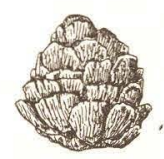

8

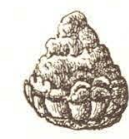

9

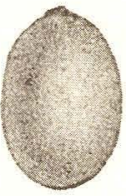

18

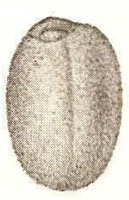

17
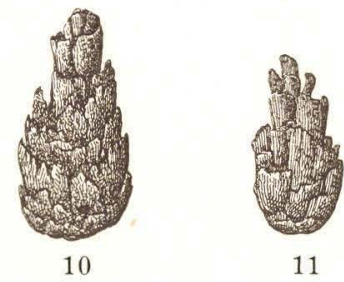

11

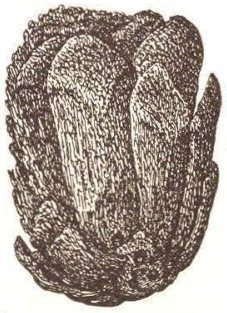

7

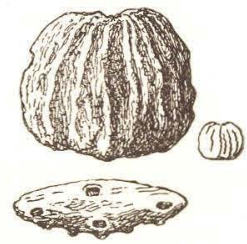

16

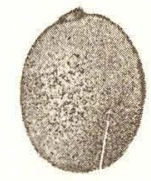

19

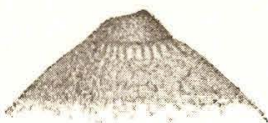

20

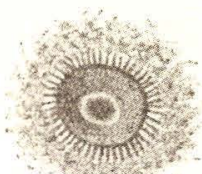

21
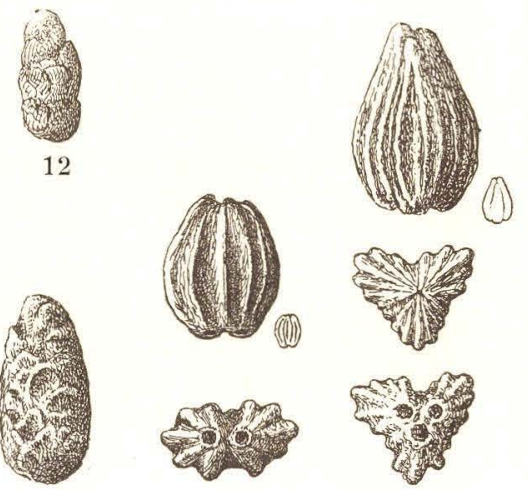

15 
Tavle VI 


\section{Planter m. m. fra interglacial Mose i Brørup Stationsby.}

Fig. 1. Osmunda regalis. Velbevaret Rhizom. $\frac{1}{2}$. S. 147 .

Fig. 2. Osmunda regalis. Destruereret Rhizom; sorte, sylformede KarstrængBundter liggende i Sphagnumtorv. $\frac{1}{2}$. S. 143.

Fig. 3. Osmunda regalis. Bladfragment. $\frac{1}{1}$. S. 147.

Fig. 4. Enodium (Molinia) coeruleum. Rhizom med knoldformet opsvulmede Stængelled. $\frac{1}{1}$. S. 146.

Fig. 5. Drosera rotundifolia. Frø, stærkt forstørret. S. 148.

Fig. 6. Prunus padus. Frugtsten. S. 150.

Fig. 7-11. Cervide (Cervus dama?) Ekskrementer. Fig. 7-10 fra Brørup. S. 142. Fig. 11 fra Lervad Mark. S. 182. 


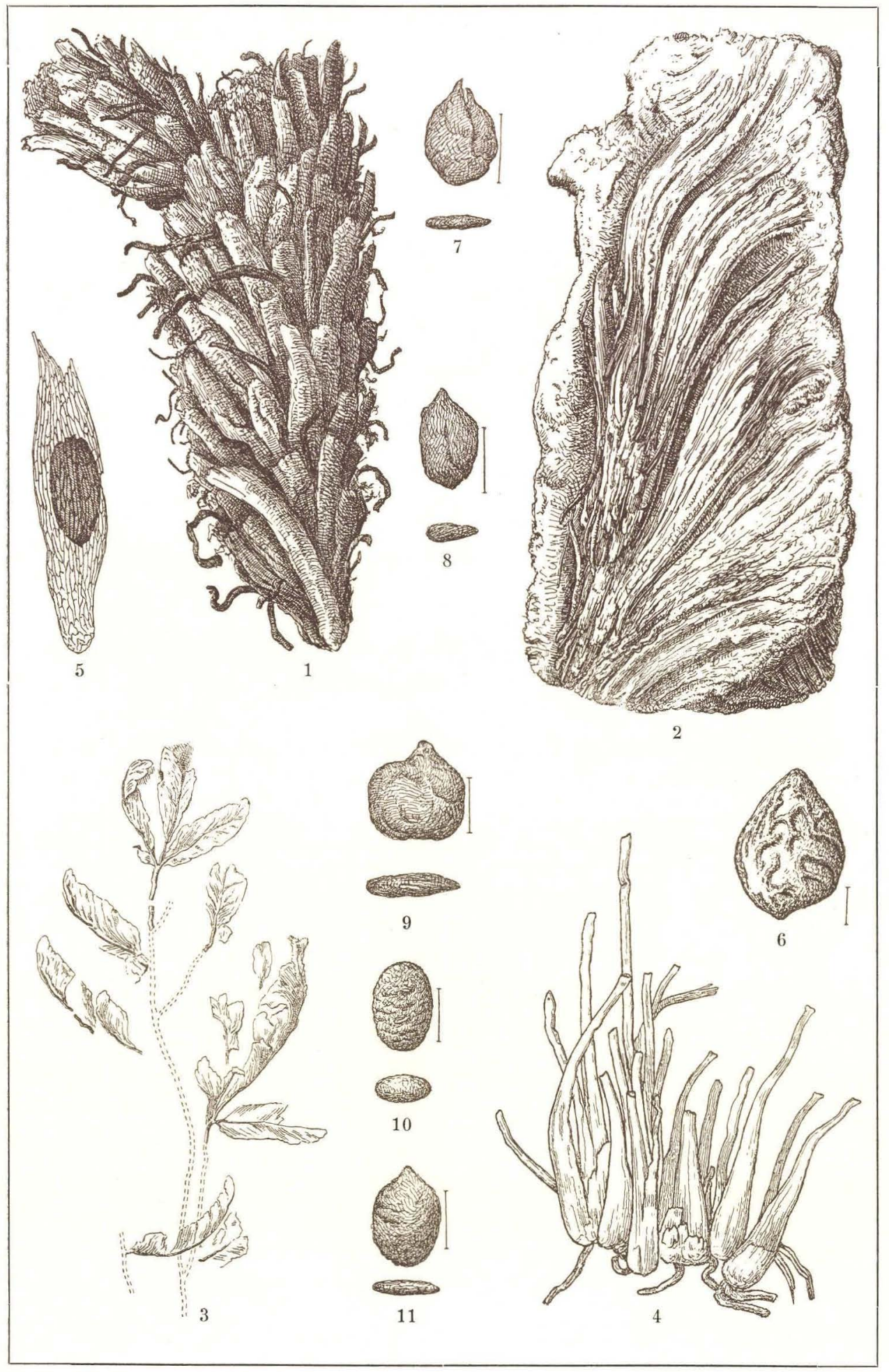


Tavle VII 


\section{Planter fra forskellige interglaciale Moser.}

Fig. 1. Empetrum nigrum. Bladbærende Grene. Brørup. $\frac{1}{1}$. S. 148.

Fig. 2. Tilia grandifolia. Kapsel. Brørup. c. $\frac{3}{1}$ og Tværsnit $\frac{1}{1}$, S. 149.

Fig. 3. Rumex maritimus. Frugt. Brørup. S. 151.

Fig. 4--6. Entorrhiza vaccinii E. Rostr., paa Rødder af Vaccinium uliginosum. 4a og 5a naturlig Størrelse, 4b og 5b $\frac{3}{1}$, 6a kugleformede, 6b ellipsoidiske Sporer. $\frac{55}{1} \pm$. Tuesbel. det. et. del. E. Rostrup. S. 166.

Fig. 7. Mycorrhiza sp. Løstliggende Mycorrhizer, 7a $\frac{1}{1}, 7 \mathrm{~b} \frac{3}{1}$. Tuesbøl. det. et. del. E. Rostrup. S. 162.

Fig. 8. Callitriche autumnalis. Bramminge, c. $\frac{20}{1}$. S. 184.

Fig. 9-12. Dulichium spathaceum. Kopier efter Britton \& Brown: An illustrated flora of the Northern United States, Canada etc., vol. I, N. York, 1896.

Fig. 13. Dulichium spathaceum. Frugt, Lervad, $\frac{1}{i}$. S. 164 og S. 183.

Fig. 14-16. Dulichium spathaceum. 14 Frugten set fra Siden, 15 set forfra, 16 en Frugt med lang, velbevaret Griffel. Lervad, c. $\frac{8}{1}$. S. 164 og 183.

Fig. 17. Populus tremula. Skovlyst, c. $\frac{5}{6}$. S. 179.

Fig. 18. Picea excelsa. Gren med Bladknop og Bladar, Tuesbel, c. $\frac{1}{1}$. 


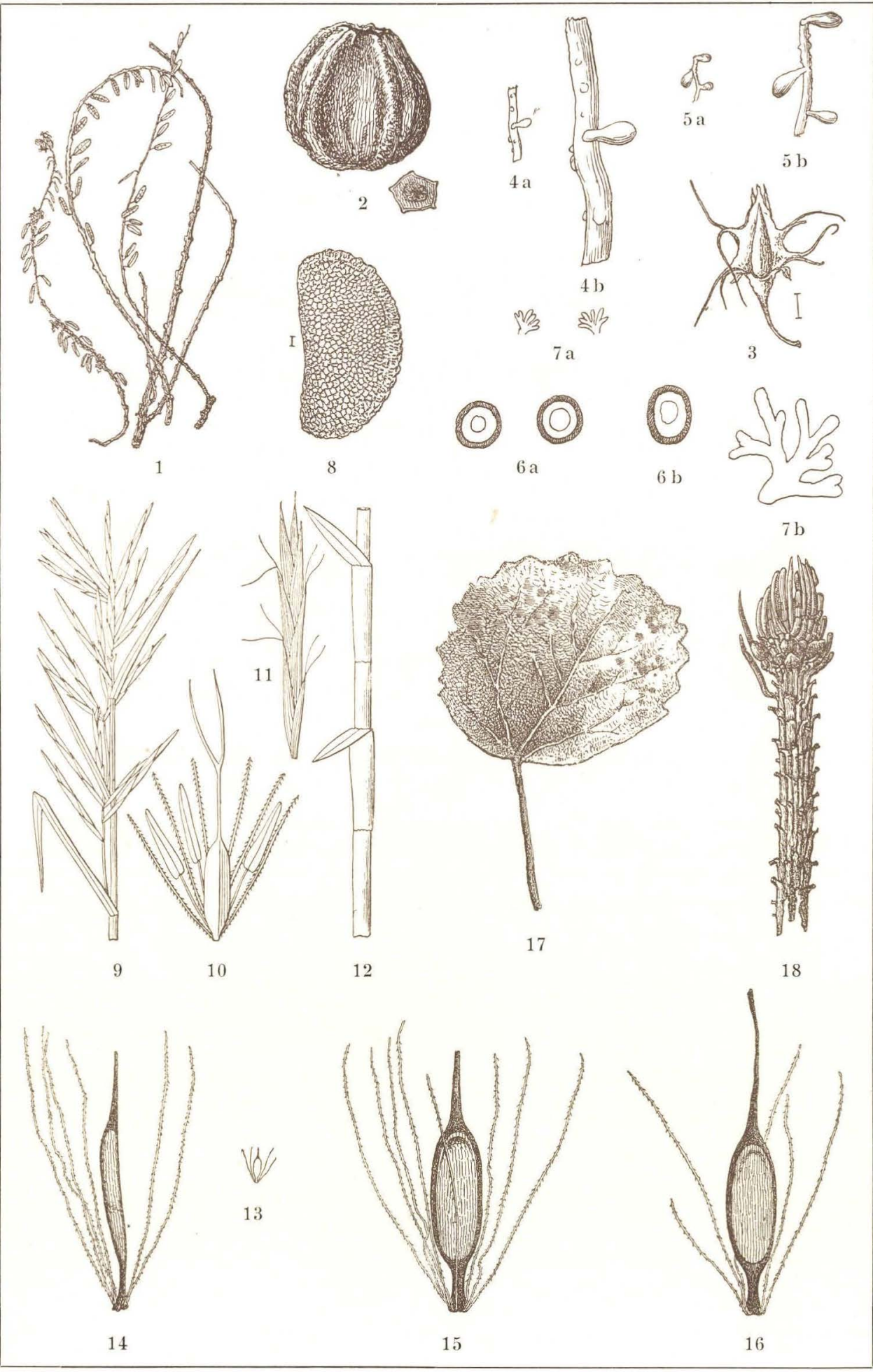


Tavle VIII 


\section{Dulichium spathaceum Pers.}

fot. Dr. P. Harder.

Fig. 1. $\frac{1}{2}$, Herbarie-Eksemplar fra Sayre, Pa., U. S. A., c. $42^{0}$ n. B. (Herb. N. Hartz.)

Fig. 2. $\frac{1}{2}$, Herbarie-Eksemplar fra Nova Scotia, U. S. A. (Mus. Bot. Hafn.) 
D. G. U. II R. Nr. 20.

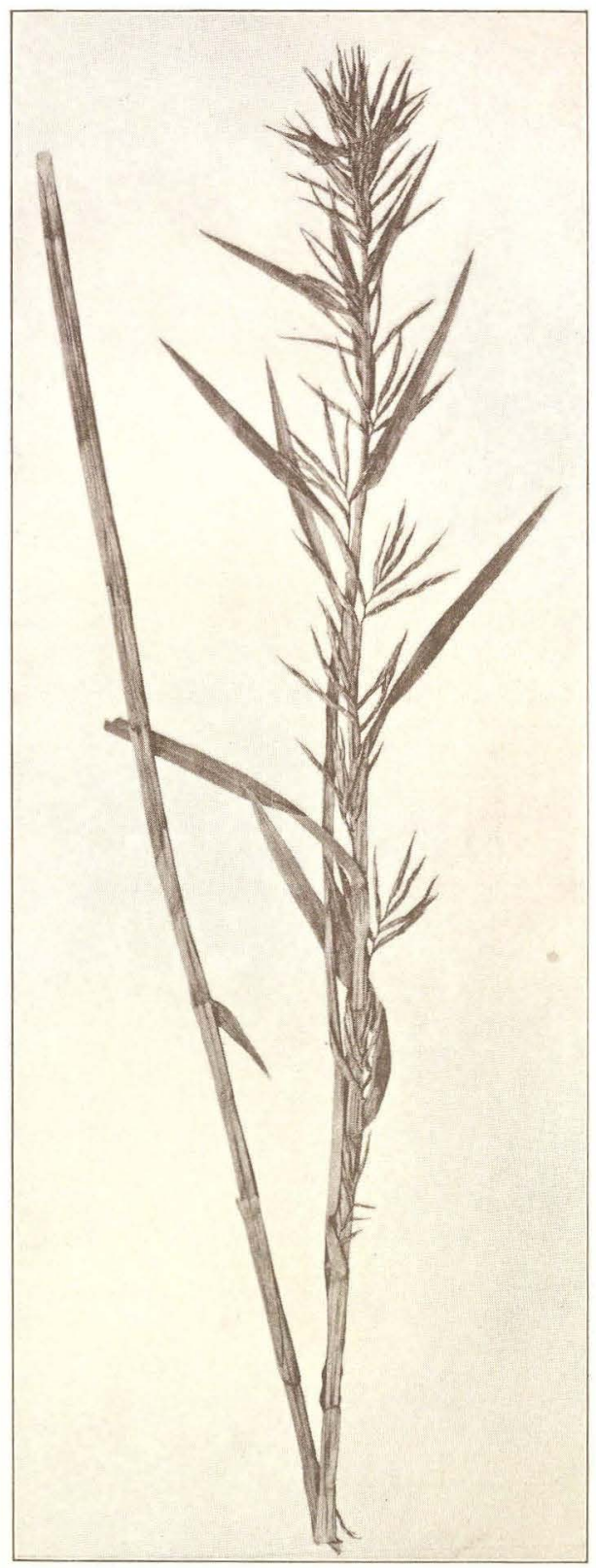

1
Tavle VIII.

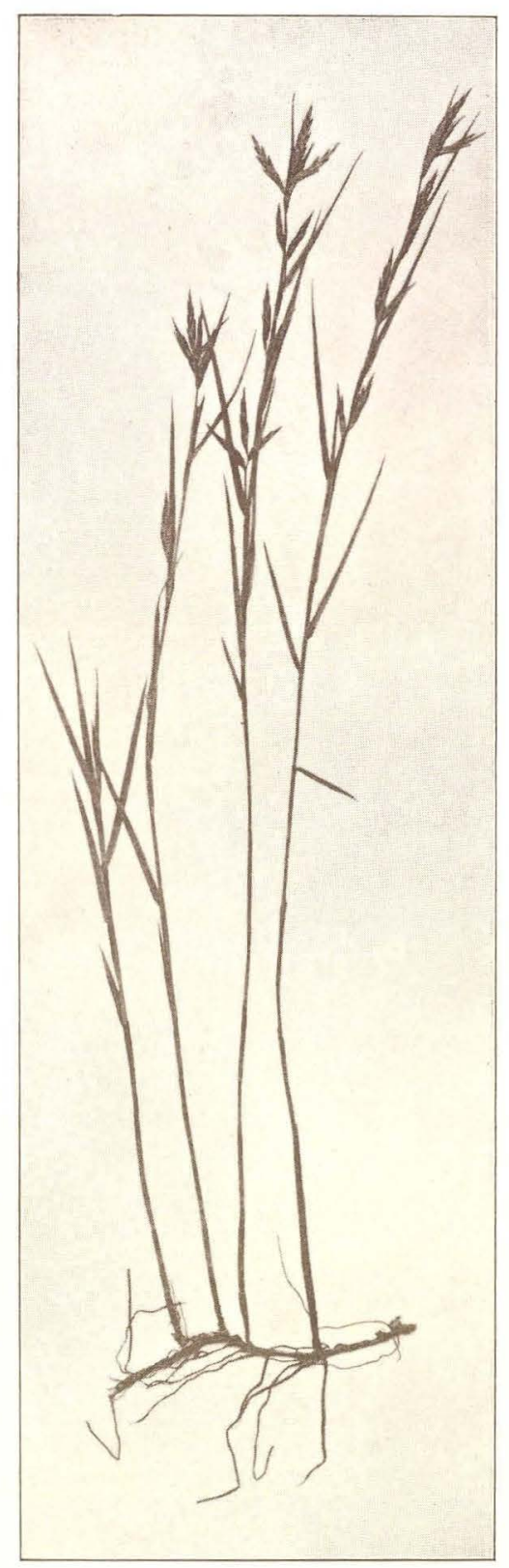

2 
Tavle IX 


\section{Planter fra interglacial Mose ved Tuesbøl m. m.}

Fig. 1-7. Stratiotes aloides. Frø, Tuesbøl. S. 170.

Fig. 8-11. Lastrcea thelypteris. Bladrester, Tuesbøl. S. 170.

Fig. 12-13. Ilex aquifolium. Blade, Tuesbøl. S. 164.

Fig. 14. Hydrocharis morsus rance. Frø, Tuesbøl. S. 173.

Fig. 15. Sparganium ramosum. Dobbelt-Frugtsten, Tislund. S. 191.

Fig. 16-18. Picea excelsa. Tuesbøl. S. 163. 


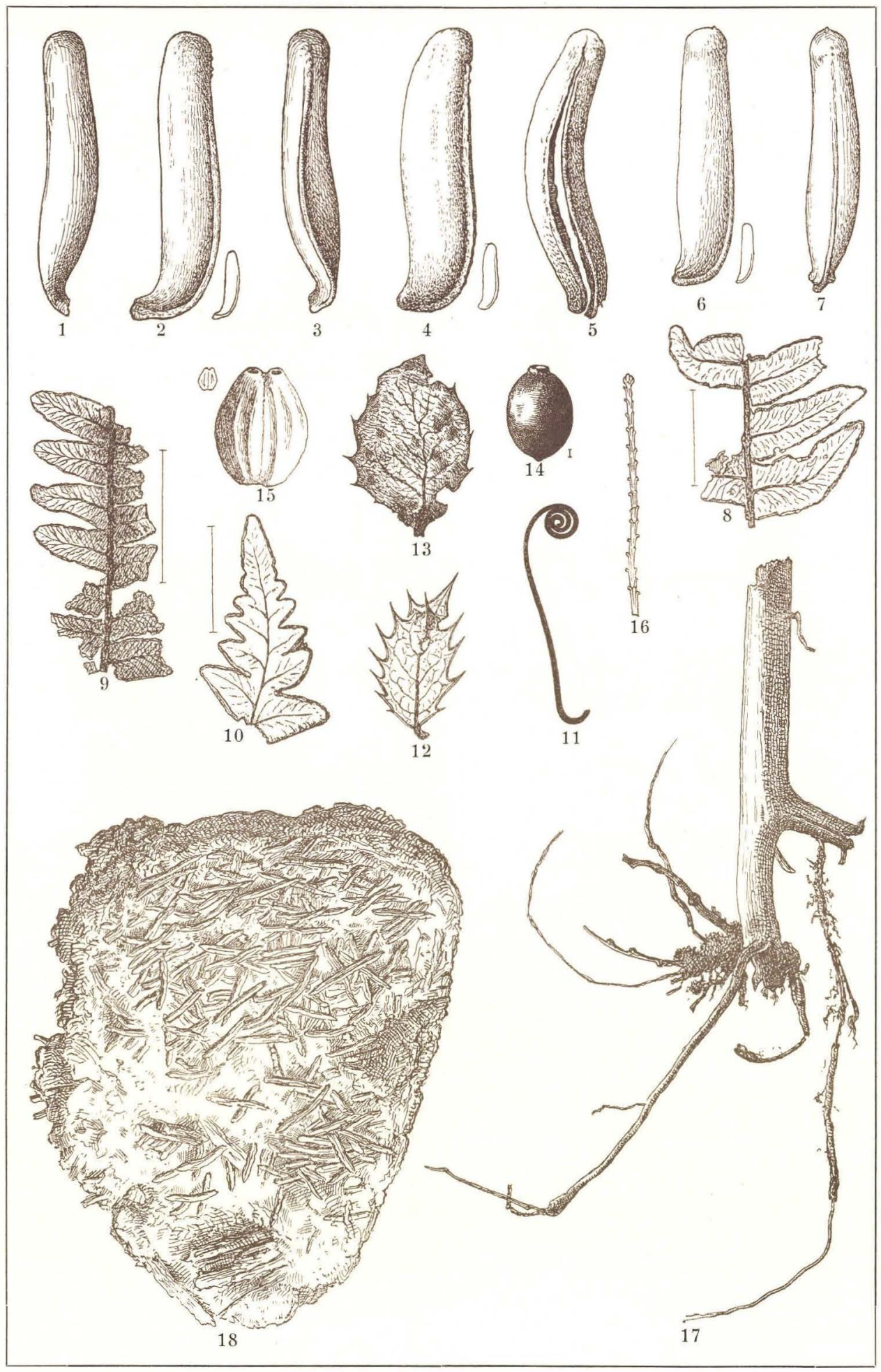


Tavle X 


\section{Fra forskellige interglaciale Moser.}

Fig. 1-2. Picea excelsa. Kogler, $\frac{1}{1}$, Bramminge. S. 185.

Fig. 3. Dulichium spathaceum. Frugt, c. $\frac{8}{1}$, Høllund Søgaard. S. 200.

Fig. 4-5. Betula nana. Blade, Høllund Søgaard. S. 200.

Fig. 6. Picea excelsa. Stencellebark, stærkt forstørret, Høllund Søgaard. S. 200.

Fig. 7-10. Eoliter. $\frac{1}{1}$, Høllund Søgaard. Fig. 7. Slagsten? (percuteur?). S. 203. Fig. 8. Skraber (racloir). S. 203. Fig. 9. Skraber? (racloir?). S. 204. Fig. 10. En Flintknold, hvoraf er afskrællet tynde Lameller. S. 204. 


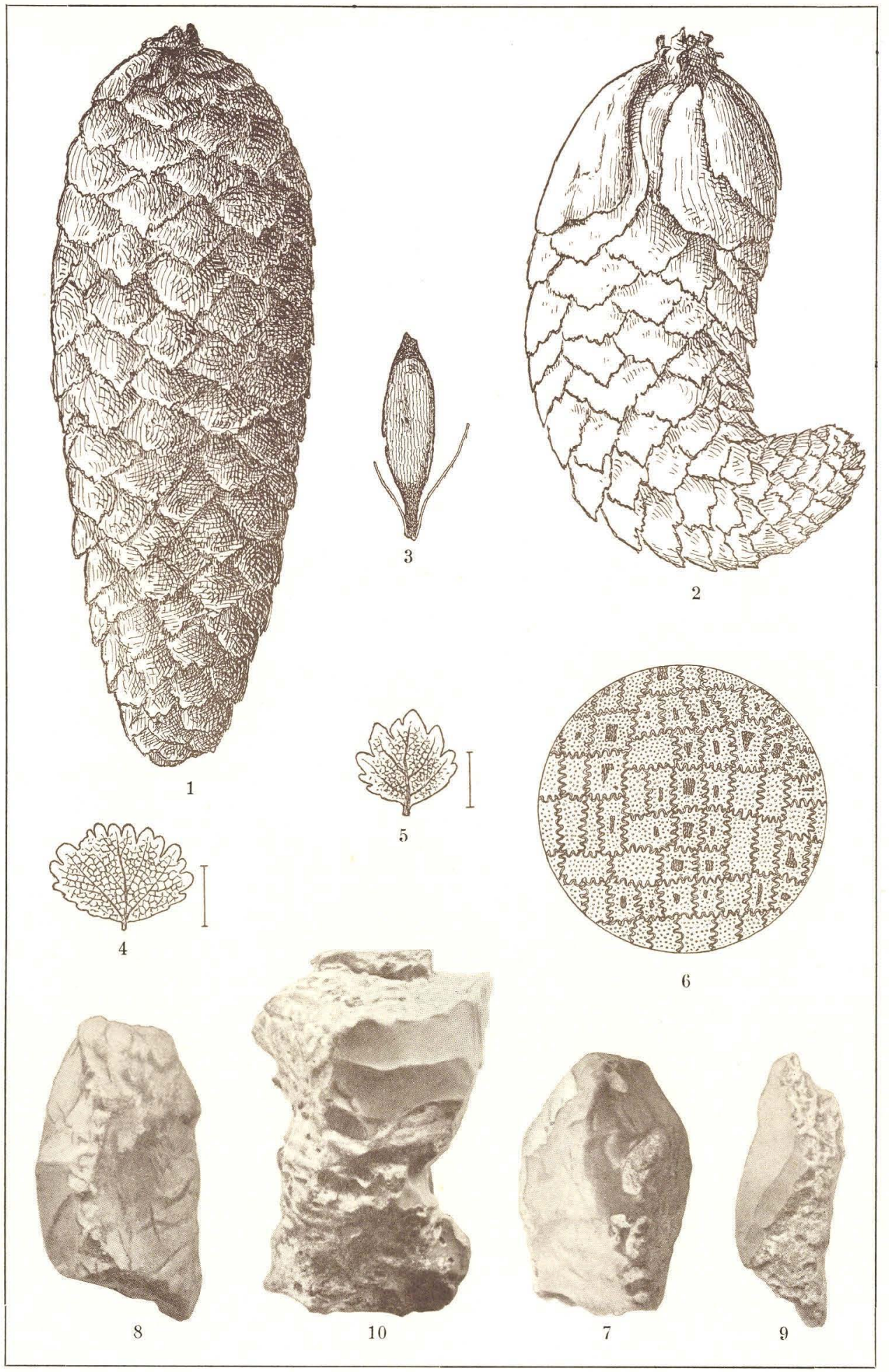


Tavle XI 


\section{Planter og Dyr fra Ejstrup.}

Fig. 1. Plumatella sp. Statoblaster paa Epiderm af Anodonta.

Fig. 2. Laag af Phryganide. Larvehylster.

Fig. 3. Piscicola sp. Ægkapsel.

Fig. 4. Taphrina alni paa Ellerakle. $\frac{2}{1}$.

Fig. 5. Gnomonia sp. paa Avnbøg-Blad.

Fig. 6. Marchantia polymorpha. Frugtstand.

Fig. 7-11. Picea excelsa. Vingede og vingeløse Frø.

Fig. 12-13. Taxus baccata. Frø.

Fig. 14-18. Populus tremula. Rakleskæl.

Fig. 19-20. Rumex sp. Frugter med og uden Bloster.

Fig. 21. Sagittaria sagittafolia. Frugt.

Fig. 22-24. Ulmus sp. Frugter og Frø.

Fig. 25. Ilex aquifolium. Tornløst Blad.

Fig. 26. Ilex aquifolium. Frø.

Fig. 27. Ajuga reptans. Frugt.

Fig. 28. Viscum album. Stængelstykke.

Fig. 29. Viscum album. Frugtskal. 
D. G. U. II R. Nr. 20.

Tavle XI.

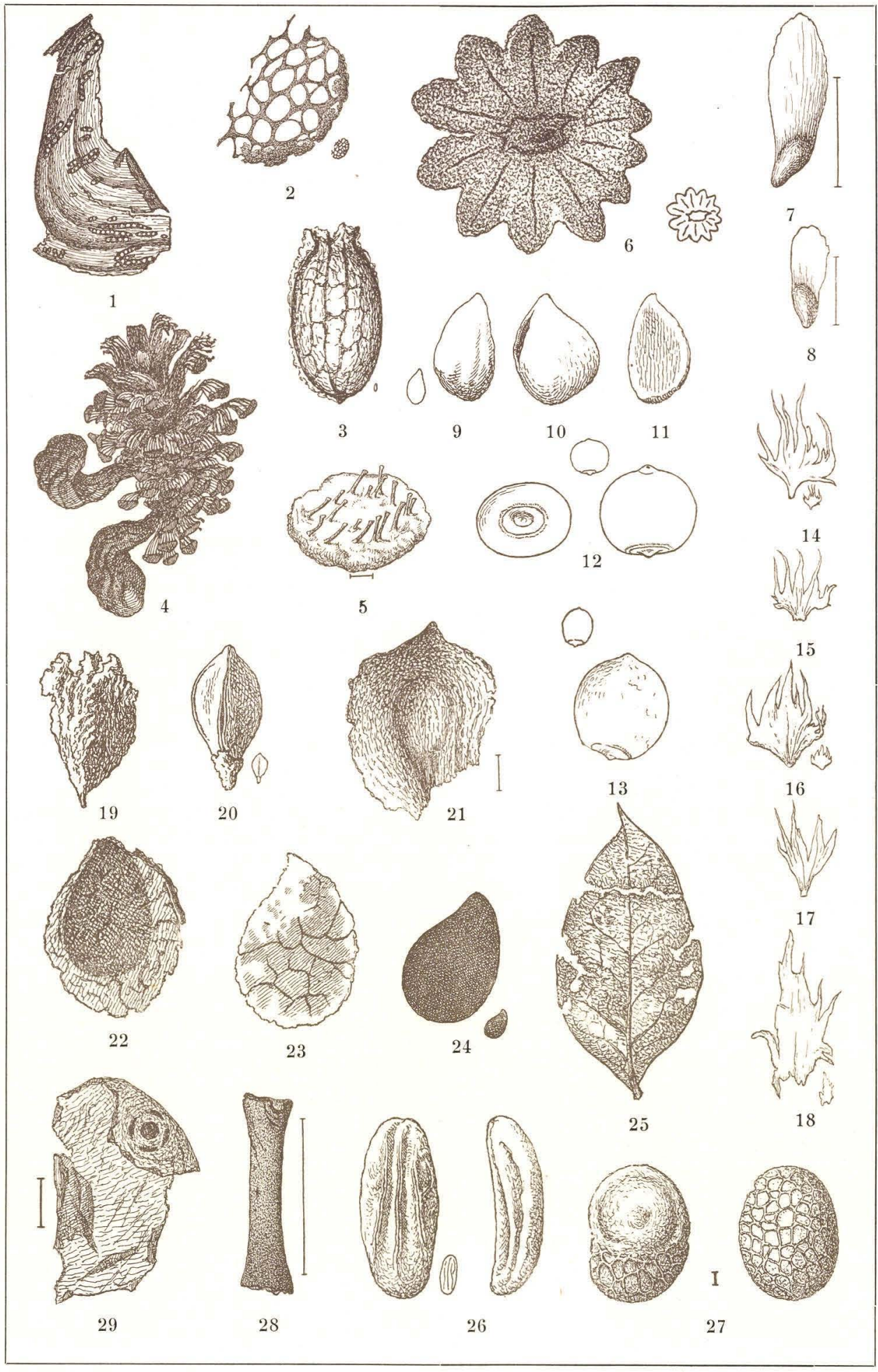


Tavle XII 


\section{Planter fra Ejstrup m. m.}

Fig. 1-2. Eupatorium cannabinum. Frugter.

Fig. 3-4. Carpinus betulus. Frugter.

Fig. 5. Acer sp. Frugt.

Fig. 6-7. Cirsium lanceolatum. Frugter.

Fig. 8. ?

Fig. 9-10. Tilia europcea. 4-rummet Frugt.

Fig. 11-12. Torilis anthriscus. Frugt.

Fig. 13-14. Oenanthe phellandrium. Frugter.

Fig. 15. Cicuta virosa?

Fig. 16-17. Carum carvi?

Fig. 18. Lycopus europceus. Frugt.

Fig. 19. Oxalis acetosella. Frø.

Fig. 20. Polygonum lapathifolium. Frugt med "Bægertorne».

Fig. 21. Sambucus sp. Frugtsten.

Fig. 22. Viola palustris. Frø.

Fig. 23-24. Rubus sp. Tornede Grene.

Fig. 25. Limnanthemum nymphœoides. Frø, Gytjeblok i nedre Moræne, Københavns Frihavn, c. $\frac{8}{1}$. S. 134.

Fig. 26. Limnanthemum nymphaoides. Frø, fra Eem-Aflejringernes Ferskvandslag, Stensigmose, Broagerland, c. $\frac{20}{1}$. S. 243. 


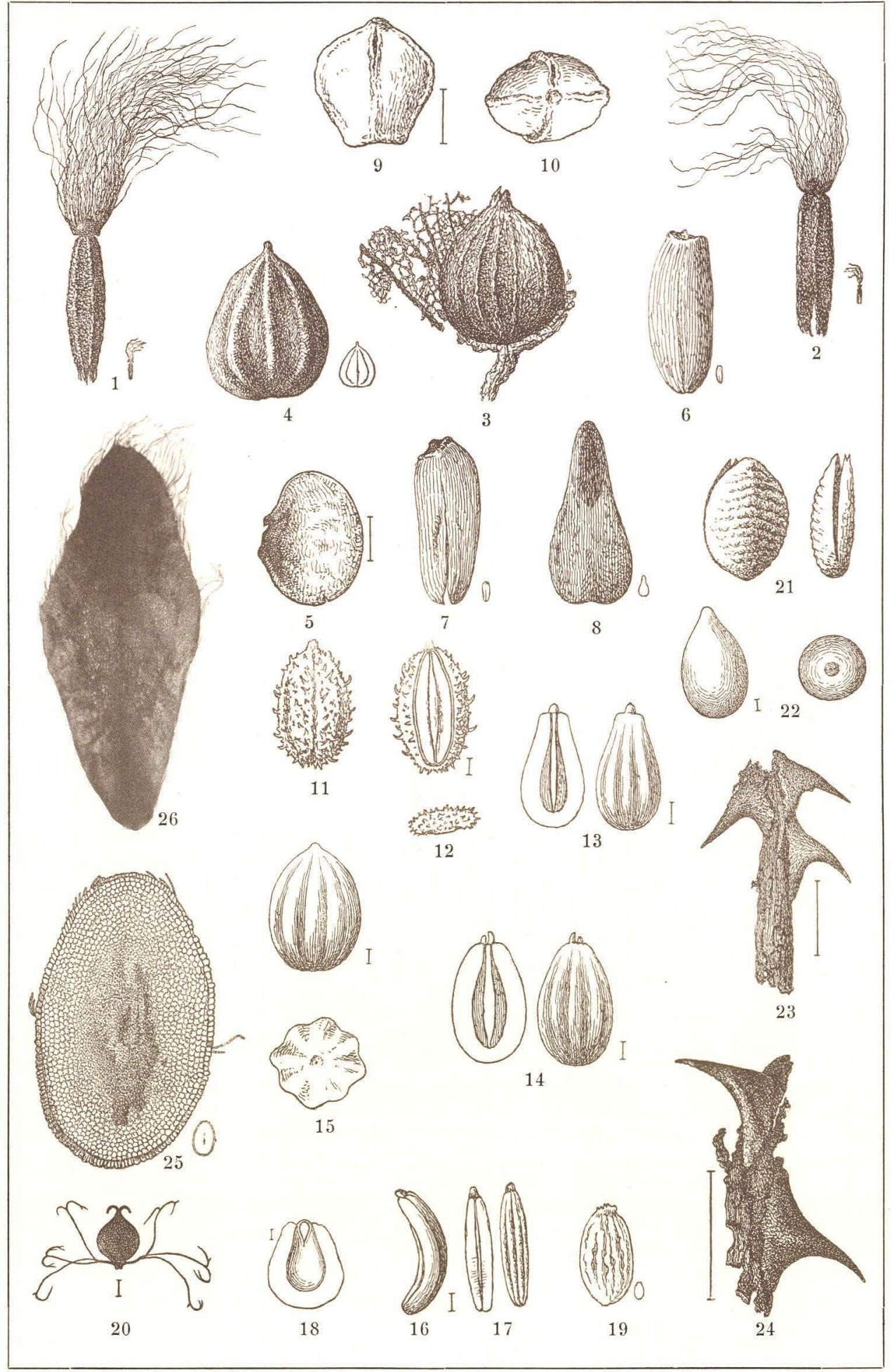


Tavle XIII 


\section{Corylus avellana}

fra forskellige interglaciale Aflejringer (tegnede med Tegneprisme), $\frac{1}{1}$. S. 250. Fig. $1-9$ f. silvestris.

Fig. $10-14$ f. ovata.

Fig. 15-25 f. oblonga.

Fig. 1, 2, 3, 6, 7, 9, 10, 13, 14, 19, 21, 22, 23, 25 fra Ejstrup.

Fig. 4, 5, 8, 11, 12, 15, 16, 17, 24 fra Brørup Stationsby.

Fig. 18 fra Lervad Mark.

Fig. 20 fra Tuesbøl Mark. 


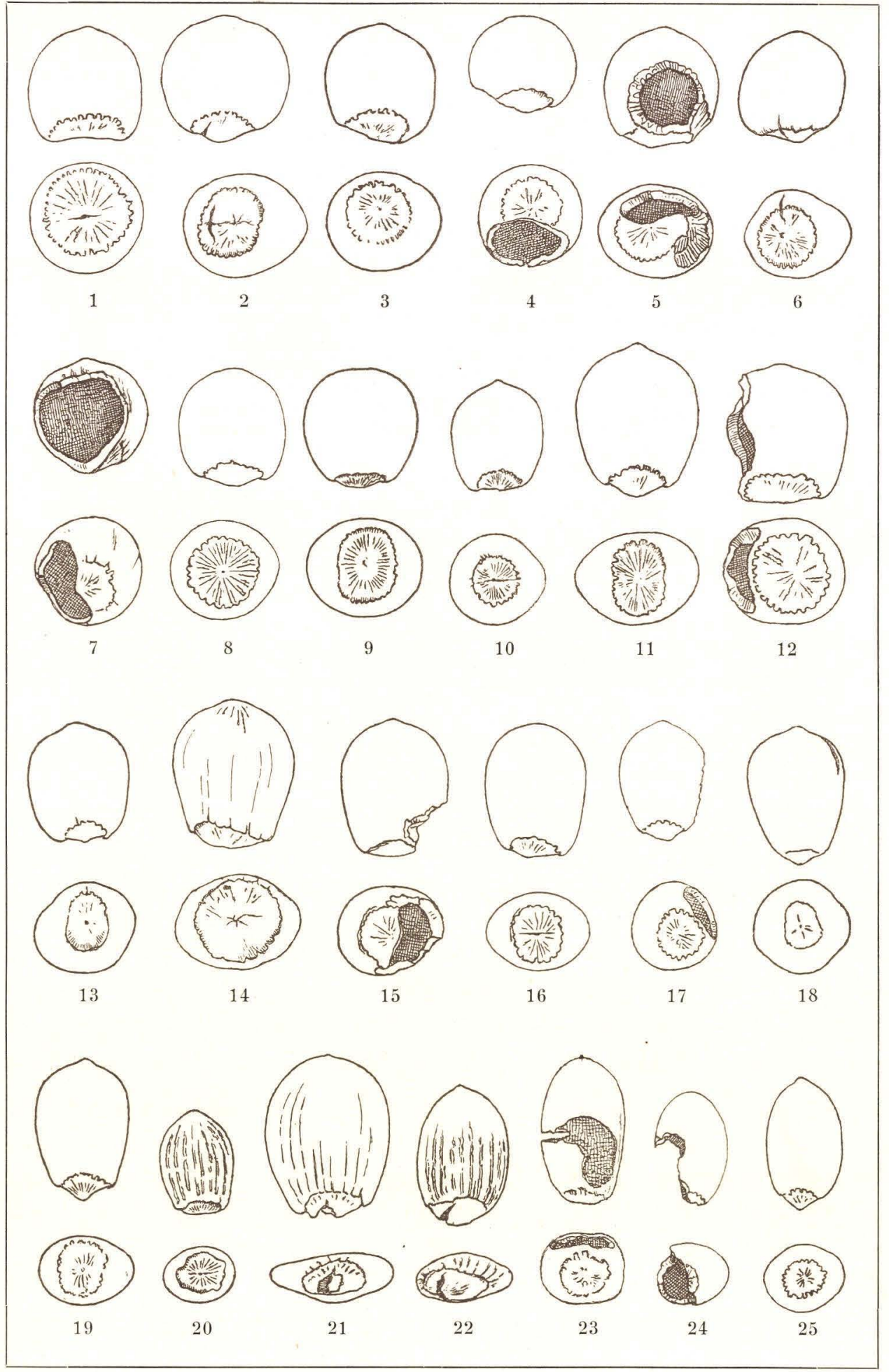


Nr. 2 K. RøвDAm Saltvandsalluviet i det nordostlige Sjæland. $1892 \ldots \ldots \ldots \ldots \ldots \ldots \ldots \ldots$ Pris $3,00 \mathrm{Kr}$.

- 3. K. Rørdam. Geologisk-agronomiske Undersøgelser ved Lyngby Landboskole og Brede Ladegaard. $1894 \ldots \ldots \ldots \ldots \ldots \ldots \ldots \ldots$. . . . . . . . . .

- 4. Henr. J. Posselt. Brachiopoderne i den danske Kridtformation. $1894 \ldots \ldots \ldots \ldots \ldots \ldots \ldots$ - 1,25 -

- 5. K. RøRDaм. Beretning om en geologisk Undersøgelse paa Frænnemark ved Svaneke paa Bornholm. $1895 \ldots \ldots \ldots \ldots \ldots \ldots \ldots \ldots$. 0,75 .

- 6. K. RøвDam. Kridtformationen i Sjæland i Terrænet mellem Kjøbenhavn og Kjøge, og paa Saltholm. $1897 \ldots \ldots \ldots \ldots \ldots \ldots \ldots \ldots-1,50$ -

- 7. K. Rørdam og C. Bartholin. Om Forekomsten af Juraforsteninger i løse Blokke i Moræneler ved Kjøbenhavn. 1897 . . . . . . . . .

- 8. Ethel G. Skeat and Victor Madsen. On Jurassic, Neocomian and Gault boulders found in

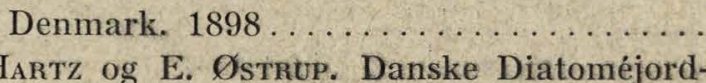
Aflejringer og deres Diatoméer. 1899....

- 9. N. Hartz og E. Østrup. Danske Diatoméjord-

- 10. Bidrag til Bornholms Geologi I. - K. A. GröNwaLL: Bemærkninger om Bornholms sedimentære Dannelser og deres tektoniske Forhold. J.P.J.Ravn: Trilobitfaunaen i den bornholmske Trinucleusskifer. A. НлоRтн: Om Vellengsbyleret og dets Flora. N. V. Ussing: Sandstengange i Granit paa Bornholm. 1899 .....................

- 11. N. Hartz. Bidrag til Danmarks senglaciale Flora og Fauna. 1902..............

- 12. N. V. Ussing .Mineralproduktionen i Danmark ved Aaret 1900. $1902 \ldots \ldots \ldots \ldots \ldots \ldots$..............

- 13. KarL A. Grönwall. Bornholms Paradoxideslag
og deres Fauna. $1902 \ldots \ldots \ldots \ldots \ldots \ldots$ $-2,00-$

- 14. Victor Madsen. Om den glaciale, isdæmmede Sø ved Stenstrup paa Fyn samt om Dannelsen af Teglværksleret i Stenstrup-Egnen. 1903 ........................... $-6,00-$

- 15. Karl A. Grönwall. Forsteningsførende Blokke fra Langeland, Sydfyn og Erø samt Bemærkninger om de ældre Tertiærdannelser i det baltiske Omraade. $1904 \ldots \ldots \ldots \ldots$ - 1,75 - 
Nr. 16. N. Steenberg og Poul Harder. Undersøgelser over nogle danske Sandsorters tekniske Anvendelighed. $1905 \ldots \ldots \ldots \ldots \ldots \ldots$ Pris $0,35 \mathrm{Kr}$.

- 17. Victor Madsen, V. Nordmann og N. Hartz.

Eem-Zonerne. Studier over Cyprinaleret og andre Eem-Aflejringer i Danmark, NordTyskland og Holland. $1908 \ldots \ldots \ldots \ldots \ldots ., 6,00-$

- 18. Karl A, Grönwall og Poul Harder, Paleocæn ved Rugaard i Jydland og dets Fauna. $1907 \ldots \ldots \ldots \ldots \ldots \ldots \ldots \ldots \ldots \ldots \ldots \ldots \ldots \ldots \ldots \ldots . .2,50$.

- 19. Poul Harder. En østjydsk Israndslinje og dens Indflydelse paa Vandløbene. $1908 \ldots \ldots .-6,00-$

\section{Række. \\ Populære Fremstillinger.}

Nr. 1. Oversigt over de af Danmarks geologiske Undersøgelse indtil Foraaret 1895 udførte Arbejder. 1896. (Udsolgt) ................

- 2. N. V. Ussing. Danmarks Geologi i almenfatteligt Omrids. Anden Udgave $1904 \ldots \ldots \ldots-4,50$ -

- 3. V. Muthers. Foreløbig Beretning om en geologisk Rejse i det nordøstlige Tyskland og russisk Polen, foretaget i Forsommeren 1901. $1902 \ldots \ldots \ldots \ldots \ldots \ldots \ldots \ldots \ldots \ldots-0,25-$

- 4. V. Mrtuers. Grundvand og vandførende Lag i Danmark, særlig med Henblik paa Forsyningen af Brønde. $1903 \ldots \ldots \ldots \ldots \ldots-1,50$ -

- 5. V. Nordmann. Danmarks Pattedyr i Fortiden. $1905 \ldots \ldots \ldots \ldots \ldots \ldots \ldots \ldots \ldots \ldots \ldots \ldots \ldots \ldots . .2,00$.

- 6. Oversigt over de af Danmarks geologiske Undersøgelse i Aarene 1895-1904 udførte Arbejder, udgivet af Kommissionen for Danmarks geologiske Undersøgelse paa Grundlag af Indberetninger fra Geologerne. $1905-1,00$ - 